\title{
Filigrane
}

Écoutes psychothérapiques

\section{Adieu Oedipe, bonjour Narcisse ? II}

\section{Sophie Gilbert et Véronique Lussier}

Volume 19, numéro 2, automne 2010

Adieu Oedipe, bonjour Narcisse ? II

URI : https://id.erudit.org/iderudit/1000453ar

DOI : https://doi.org/10.7202/1000453ar

Aller au sommaire du numéro

Éditeur(s)

Revue Santé mentale au Québec

ISSN

1192-1412 (imprimé)

1911-4656 (numérique)

Découvrir la revue

Citer ce document

Gilbert, S. \& Lussier, V. (2010). Adieu Oedipe, bonjour Narcisse ? II. Filigrane, 19(2), 7-8. https://doi.org/10.7202/1000453ar d'utilisation que vous pouvez consulter en ligne.

https://apropos.erudit.org/fr/usagers/politique-dutilisation/ 


\section{Adieu Fdipe, bonjour Narcisse? II}

\section{Sophie Gilbert et Véronique Lussier}

ans ce numéro d'automne, Filigrane prolonge le débat amorcé au printemps

dernier sur la pertinence de la référence oedipienne, en cette époque où les enjeux narcissiques paraissent s'imposer tant dans les diverses figurations du caractère que dans les repères métapsychologiques de la psychopathologie.

À cette question complexe, nos auteurs ont choisi de répondre dans des styles variés, où se côtoient des propos didactiques, argumentatifs, cliniques ou même historiques. Il en ressort un éloge à la diversité ; diversité des points de vue sur cette question forcément actuelle pour tous les cliniciens, mais aussi diversité des référents théoriques, voire même épistémologiques, de chacun.

Dans un premier temps, Catherine Chabert dépeint un oedipe encore bien vivant, mais non univoque, et articulé avec des enjeux dits pré-oedipiens, autour d'angoisses relatives à la perte d'amour de l'objet. Sa démonstration métapsychologique et clinique repose sur une référence attentive à la subtilité de l'œuvre freudienne, en confirmant l'incontournable condensation des expériences infantiles les plus précoces et des enjeux oedipiens ultérieurs, dans la perspective développementale d'étayage si chère au père de la psychanalyse.

Gilles Chagnon nous propose de suivre l'errance d'CEdipe à Colone, en empruntant les chemins méconnus de sa descendance. En parallèle, se dessine la conflictualité de la filiation psychanalytique freudienne, conflictualité qui depuis les premières rivalités et ruptures autour de Freud jusqu'aux scissions répétées de l'institution ont régulièrement remis en question, explicitement ou de façon voilée, la référence au sexuel. De l'énergie psychique associée à la technique somatique de Reich, à la référence lacanienne au Réel et à la Jouissance, quel apport pour une clinique où depuis toujours, la tentation est forte de céder au déni?

C'est du point de vue original de la posture du psychanalyste, que Sylvie Benzaquen a d'abord choisi d'aborder le thème proposé. Posture induite par les supposées «demandes » actuelles : la plainte, la quête de la jouissance immédiate et totale en tant que défense, empreinte de déliaison, contre la pulsion de mort. Que devient dans ce contexte le travail psychanalytique basé sur le transfert et autres manifestations de l'inconscient? Sous une apparence de non référence à l'oedipe, il pourrait y avoir, à l'inverse, une demande de structuration à faire émerger en recréant un lien, mais d'abord une langue commune et ainsi, adressée.

En référence à un cas clinique exemplaire, Carole Bach élabore l'articulation des conflictualités narcissiques et oedipiennes dans la pratique clinique auprès d'une 
clientèle souffrant de pathologies narcissiques-identitaires. Dans l'optique d'une modulation de l'aménagement de la cure classique, l'auteure explicite, et surtout exemplifie, la possibilité de suppléer à la non-rencontre et au traumatisme primaire par un travail psychanalytique progressif où l'analyste acceptera d'occuper la place de l'autre primordial jadis défaillant. Ainsi, le sujet-analysant pourra aspirer, si ce n'est à une résolution oedipienne organisatrice, du moins, aux prémisses - fantasme originaire de la scène primitive, conflictualité, triangulation, etc. - de ce pôle organisateur du fonctionnement psychique.

Pour François Duparc, Edipe court toujours... L'auteur le suit dans cette course par un propos percutant qui met de l'avant l'intemporalité du mythe, voire même, son ubiquité tant les enjeux actuels de la psychopathologie ne sauraient être dissociés de leurs référents métapsychologiques, notamment des fantasmes originaires inhérents à toute structure familiale. Confronté aux traumatismes familiaux qui teintent la clinique actuelle, le psychanalyste serait amené à intégrer à sa pratique les fondements socioculturels de la psyché; gardien du temps, et co-créateur de la (re) construction de l'histoire du sujet, il se porterait garant du maintien de la référence à la structuration familiale générationnelle.

Au moment de clore ce dossier, en surplomb de la question d'un Narcisse dont les éclats sembleraient voiler la valeur heuristique de la référence à l'CEdipe, on pourrait arguer que ces témoignages d'une psychanalyse complexe et plurielle illustrent somme toute ce qui pourrait bien en être la plus précieuse des spécificités.

Signalons en terminant que dans la poursuite du récent renouvellement de la revue, nous inaugurons ce mois-ci une nouvelle rubrique: «Polémique», laquelle invite à prendre part aux débats actuels en psychanalyse en permettant de commenter dans un style plus libre certaines questions controversées. 